\title{
Influência de espécies exóticas invasoras na regeneração natural de um fragmento florestal urbano
}

Influence of invasive alien species in natural regeneration of an urban forest fragment

\author{
F. Z. Miyamura; R. Manfra; G. A. D. C. Franco; R. Esteves; S. C. P. M. Souza*; \\ N. M. Ivanauskas
}

Instituto Florestal, Rua do Horto, 931, 023777-000, São Paulo-SP, Brasil

*silvana1souza@gmail.com

(Recebido em 19 de fevereiro de 2019; aceito em 23 de julho de 2019)

\begin{abstract}
As espécies exóticas invasoras ameaçam a manutenção da biodiversidade, pois podem ocupar o espaço das nativas e dominar grandes extensões. O objetivo deste estudo foi avaliar a regeneração secundária no Parque Estadual Alberto Löfgren, São Paulo - SP, e a influência das espécies exóticas invasoras na sucessão. Foram instaladas 22 parcelas de $100 \mathrm{~m}^{2} \mathrm{e}$, em cada uma, 10 subparcelas de $1 \mathrm{~m}^{2}$ para amostragem do estrato regenerante. Foram coletados dados dos indivíduos de altura maior ou igual a $20 \mathrm{~cm}$ e diâmetro na altura do solo menor que $5 \mathrm{~cm}$. Os indivíduos amostrados foram distribuídos em grupos funcionais de polinização, dispersão e sucessão. Foram registrados 1.150 indivíduos, distribuídos em 93 espécies (21\% exóticas), 86 gêneros e 48 famílias. A maior parte das espécies são polinizadas $(84 \%)$ e dispersas (61\%) por animais. Apesar do estrato regenerante apresentar grupos funcionais compatíveis com a trajetória sucessional progressiva, o destaque das exóticas nos parâmetros fitossociológicos foi expressivo, o que evidencia competição com a regeneração nativa e pode retardar o processo de sucessão ecológica na área.

Palavras-chave: invasão biológica, manejo, áreas protegidas.
\end{abstract}

Invasive alien species threaten the maintenance of biodiversity, as they can occupy the native space and dominate large expanses. The objective of this study was to evaluate the secondary regeneration in the Alberto Löfgren State Park, São Paulo - SP, and the influence of the invasive alien species in the succession. A total of 22 plots of $100 \mathrm{~m}^{2}$ were installed, and in each one 10 subplots of $1 \mathrm{~m}^{2}$ were used to sample the regenerating stratum. Data were collected from individuals of height greater than or equal to $20 \mathrm{~cm}$ and diameter at soil height less than $5 \mathrm{~cm}$. The individuals sampled were distributed into functional groups of dispersion, pollination and succession categories. There were 1,150 individuals, distributed in 93 species ( $21 \%$ exotic), 86 genera and 48 families. The majority of plants are pollinated (84\%) and dispersed (61\%) by animals. Although the regenerating stratum presented functional groups compatible with the progressive successional trajectory, the highlight of the exotic species in the phytosociological parameters was expressive, which shows a competition with the native regeneration and may delay the succession process. Key-words: biological invasion, management, protected areas.

\section{INTRODUÇÃO}

Técnicas de prevenção e detecção precoce são sempre o meio mais eficaz de controle de invasões biológicas [1]. No entanto, recursos e esforços também são necessários para a erradicação ou controle de espécies invasoras nos ecossistemas naturais já invadidos, com critérios claros para diferenciar populações que requerem ações de manejo e, assim, otimizar a alocação de recursos humanos e financeiros [2].

No caso de plantas exóticas introduzidas em ecossistemas naturais, torna-se necessária a avaliação do impacto dessas populações sobre a composição, estrutura ou processos ecológicos mantenedores da comunidade vegetal ali existente. Miller e Bestelmeyer (2016) [3] argumentam que, mesmo que a remoção de todas as espécies introduzidas seja possível, nem sempre é desejável, pois pode facilitar a invasão por outras espécies exóticas $[4,5,6]$ ou essas espécies podem ter assumido funções valiosas em alguns ecossistemas [7, 8, 9]. Como exemplo, pinheiros exóticos (Pinus pineaster Aiton) são utilizados como fonte alimentar para a cacatua-negra (Calyptorhyncus baudinii Lear) no Sudoeste da Austrália, o que torna o manejo da espécie invasora dependente da reconstrução de habitat para essa população de aves [10]. 
Para aquelas diagnosticadas como invasoras dominantes, ou seja, que podem deslocar espécies nativas e efetivamente causar perdas de biodiversidade ou mudanças no funcionamento do ecossistema, são prioritários os experimentos para definição de práticas de manejo viáveis para erradicação das invasoras e restauração de habitats [2]. O tema é ainda mais relevante para áreas protegidas, pois estudos com essa finalidade são essenciais para subsidiar planos de manejo. Infelizmente, a erradicação de plantas invasoras pode ser tecnicamente impossível ou economicamente inviável, caso a invasão já tenha ultrapassado limites passíveis de manejo [9].

Limiares irreversíveis são reconhecidos pela ciência da Restauração Ecológica, mas prever quando um limiar será ultrapassado e o grau de reversibilidade é tema de ampla discussão na comunidade acadêmica. Nesse cenário, o uso do termo neoecossistema (novel ecosystem) foi motivo de debate na ocasião em que Hobbs et al. (2006, 2009) [7, 8] o empregaram para definir sistemas cujas características bióticas e/ou abióticas tenham sido alteradas, como resultado de modificações humanas em ecossistemas naturais ou do abandono de sistemas previamente manejados. Por definição, um "novo ecossistema" refere-se a uma nova combinação de espécies, que surge de forma espontânea e irreversível em resposta a mudanças antropogênicas no uso da terra, por introduções de espécies e/ou mudanças climáticas, sem correspondência com qualquer ecossistema historicamente conhecido [11]. Também denominado de "ecossistema emergente" $[12,7]$, o conceito de neoecossistemas se aplica para áreas em que as atividades humanas facilitaram a disseminação de exóticas, dando origem a novas combinações de espécies vegetais e/ou animais e, portanto, neocossistemas.

Para Miller e Bestelmeyer (2016) [3] é importante diferenciar neoecossistemas de ecossistemas híbridos, pois este último pode ser restaurado mais prontamente a um estado anterior à degradação, enquanto neoecossistemas cruzaram um limiar além do qual a restauração é, na melhor das hipóteses, muito improvável [13]. Portanto, a existência de limiares "irreversíveis" separam os ecossistemas híbridos dos neoecossistemas, além do qual a restauração é impossível [11].

Considerando esta conjuntura, é importante selecionar indicadores ecológicos adequados para a caracterização e o monitoramento de ecossistemas naturais já invadidos por plantas exóticas, a fim de verificar se a área em questão se ajusta a um neoecossistema ou a um ecossistema híbrido, para o qual recomendações de possíveis ações práticas de manejo adaptativo possam aumentar a eficiência dos processos ecológicos envolvidos com a restauração e, consequentemente, reduzir os seus custos $[14,15]$.

Bons indicadores são variáveis que podem ser medidas com facilidade e precisão para o monitoramento das alterações na biodiversidade ou nos processos ecológicos do ecossistema em restauração, ao longo de sua trajetória em relação ao estado desejado ou ao estado inicial documentado [16]. Para florestas naturais alvos de invasão biológica, a necessidade ou não de aplicação de técnicas de manejo adaptativo baseia-se na avaliação de sua trajetória ecológica. Assume-se o princípio ecológico de que o sucesso do projeto está baseado no restabelecimento das espécies nativas e dos processos ecológicos que permitam garantir a autossustentabilidade dos ecossistemas restaurados [17]. Nesse contexto, o diagnóstico do estrato regenerante assume importância relevante: o monitoramento regular da composição florística e da estrutura da comunidade presente no subosque é importante para definir se essa floresta inclina-se a uma mudança progressiva.

Plantas exóticas podem comprometer o estabelecimento e a regeneração de populações naturais e, eventualmente, dominar a comunidade, especialmente em paisagens muito perturbadas [18]. Para áreas protegidas, é relevante que a ciência apresente as melhores práticas para embasar políticas públicas relacionadas à conservação da biodiversidade, com metas claras para a restauração e estratégias para alcançá-las. Nesse contexto, a preocupação quanto à invasão biológica e a necessidade de se adotar medidas de controle de suas populações tem sido claramente expressas nos planos de manejo de unidades de conservação. Na região metropolitana de São Paulo, plantas invasoras foram registradas no Parque Estadual da Cantareira [19], Parque Estadual do Jaraguá [20] e Parque Estadual das Fontes do Ipiranga [21, 22].

No Parque Estadual Alberto Löfgren (PEAL), os maiores valores de importância da comunidade arbórea de um trecho de Floresta Ombrófila Densa foram ocupados por espécies exóticas [23]. A fim de complementar as informações já obtidas, este estudo buscou avaliar a 
regeneração de um trecho de vegetação secundária nessa mesma unidade de conservação de proteção integral, a fim de verificar se há indícios de que as plantas exóticas estejam prejudicando a trajetória sucessional progressiva da floresta. Constatada a influência da invasão biológica na regeneração natural da comunidade, discutiu-se o enquadramento da área num ecossistema híbrido ou num neoecossistema, com implicações para o plano de manejo.

\section{MATERIAL E MÉTODOS}

\section{1 Área de estudo}

O Parque Estadual Alberto Löfgren (PEAL; 2327'32'S e 46³8'11'W) está situado no município de São Paulo, com altitudes entre 770 e $825 \mathrm{~m}$. O clima na região é mesotérmico e úmido com verão chuvoso e inverno seco (Cwa no sistema de Koeppen), a temperatura média é de $19,9^{\circ} \mathrm{C}$ e a precipitação média anual é de $1.322 \mathrm{~mm}$, sendo o mês mais chuvoso janeiro $(229,8$ $\mathrm{mm})$ e o mais seco agosto $(31,7 \mathrm{~mm})$ [24]. O presente estudo foi realizado na microbacia do Córrego do Viveiro, a qual possui 49,07 hectares, na sua totalidade antropizada, identificada parte como Zona de Uso Especial e parte como Zona de Recuperação no Plano de Manejo do PEAL [24].

Situa-se no Planalto Atlântico [25], com predomínio do Argissolo Vermelho-Amarelo e Latossolo Vermelho-Amarelo [26]. A vegetação do PEAL é considerada de transição entre Floresta Ombrófila Densa Montana e Floresta Estacional Semidecidual [27, 28, 29].

Cerca de $42 \%$ do PEAL é composto por talhões, glebas e parcelas com plantios monoespecíficos ou com até quatro espécies em consórcio de nativas e exóticas. O subosque desses plantios apresenta regeneração natural heterogênea de espécies nativas e exóticas [24].

\subsection{Coleta de dados}

A amostragem fitossociológica foi realizada por meio do método de parcelas, em sete hectares de Floresta Ombrófila Densa secundária em processo de regeneração natural, os quais já foram alvo de levantamento fitossociológico do estrato arbóreo em Souza et al. (2016) [23]. Nesta área foram sorteadas 22 parcelas de $10 \times 10 \mathrm{~m}$ e, no interior de cada uma, instaladas 10 subparcelas circulares de $1 \mathrm{~m}^{2}$ para a análise do estrato regenerante, totalizando $220 \mathrm{~m}^{2}$ de área amostral (Figura 1).

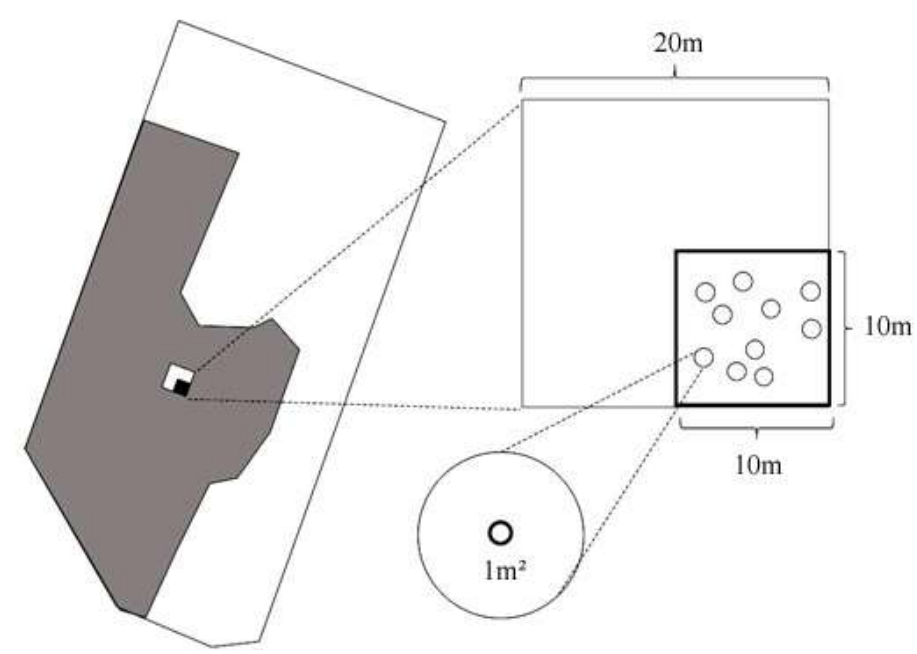

Figura 1: Esquema do delineamento experimental, em cinza a área em que foram distribuídas as parcelas; em detalhe as unidades experimentais alvo de levantamento fitossociológico do estrato arbóreo

(Souza et al. 2016), na qual foi instalada parcela permanente de $10 \times 10 \mathrm{~m}$ para análise do estrato regenerante, por meio de amostragem de 10 subparcelas circulares de $1 \mathrm{~m}^{2}$.

Foram incluídos no levantamento os indivíduos com altura maior ou igual a $20 \mathrm{~cm}$ e diâmetro ao nível do solo (DAS) inferior a $5 \mathrm{~cm}$, de cada indivíduo, foi registrado a altura; o diâmetro do 
caule na altura do solo (DAS) e o índice de cobertura da copa a partir dos valores da escala de Braun-Blanquet [30], na qual são fixados valores de 0 a 5 de acordo com a cobertura de cada espécie na subparcela.

A maior parte dos indivíduos amostrados no estrato regenerante foi identificado em campo, com base na lista das espécies locais elaborada por Souza et al. (2016) [23]. Quando a identificação em campo não foi possível, parte da planta (ramo ou folha) foi coletada para identificação posterior. A fim de evitar amostragens destrutivas de indivíduos muito pequenos, estes foram fotografados e, quando a imagem fotográfica não permitiu identificação, foi realizada a coleta do material de mesma morfoespécie fora das parcelas amostrais para posterior identificação. Os indivíduos coletados foram comparados com o material do Herbário SPSF e/ou confirmados por especialistas; quando não se chegou a uma identificação, foram agrupados em morfoespécies. A circunscrição em famílias e os nomes científicos foi checada na Lista de Espécies da Flora do Brasil - BFG (2018) [31].

As plantas foram classificadas de acordo com seu hábito de crescimento [28]: "árvore" - planta lenhosa que ramifica acima de $0,5 \mathrm{~m}$ e que atinge $3,0 \mathrm{~m}$ de altura ou mais, ocorrendo no subdossel, dossel ou emergente; "palmeira" - planta que apresenta caule do tipo estipe; "arbusto" - planta pequena, de base lenhosa, que ramifica abaixo de 0,5 m de altura; "erva" - toda planta herbácea e terrestre que compõe o estrato herbáceo; "trepadeira" - toda planta de hábito escandente ou volúvel de forma ampla, tanto herbácea quanto lenhosa; e "hemiepífita" - planta que se apresenta na condição epifítica apenas durante parte do seu ciclo de vida.

$\mathrm{O}$ estrato regenerante foi subdividido em dois componentes, os quais competem pelos mesmos recursos nas fases iniciais de desenvolvimento: o componente residente e o transiente. Espécies de plantas residentes habitam o subosque desde a fase de plântula até a idade adulta, enquanto as transientes permanecem no subosque apenas na fase juvenil, pois atingem a maturidade nos estratos superiores [32]. No componente residente foram incluídas as ervas, as trepadeiras herbáceas, os pequenos arbustos e as pequenas árvores, sendo que para estes dois últimos hábitos foram consideradas de pequeno porte as plantas que usualmente não atingem o critério de inclusão adotado em levantamentos fitossociológicos em Floresta Atlântica $(5 \mathrm{~cm}$ de diâmetro a 1,30m do solo). No componente transiente foram incluídas as trepadeiras lenhosas, hemiepífitas, palmeiras, árvores e arbustos presentes no estrato regenerante, mas com potencial de atingir o componente denominado de adulto por Souza et al. (2016) [23].

Foi adotado o conceito de espécie nativa apresentado por Moro et al. (2012) [33]. A distribuição geográfica de cada espécie foi baseada na sua formação vegetal de origem, obtida a partir da Lista de Espécies da Flora do Brasil - BFG (2018) [31], estandardizada conforme o sistema oficial de classificação da vegetação brasileira [34] e conferida de acordo com os pontos de ocorrência em formações naturais disponíveis na base de dados do INCT- Herbário Virtual da Flora e dos Fungos [35]. Desta forma, as espécies classificadas como nativas foram aquelas com ocorrência natural em Floresta Ombrófila Densa ou em área de ecótono a esta formação na cidade de São Paulo [36].

Foram consideradas exóticas as espécies transportadas de uma dada região geográfica para outra em que não ocorreriam naturalmente, independente de seu eventual impacto sobre os ecossistemas nativos, sendo o transporte realizado por ação humana intencional ou acidental [37]. Neste grupo foram incluídas todas as espécies de ocorrência fora dos limites geográficos historicamente reconhecidos para as formações naturais do município de São Paulo [33] e ausentes na lista oficial de espécies nativas no estado de São Paulo [38]. Em geral, foram consideradas exóticas aquelas provenientes de outro país ou de ocorrência restrita a outra tipologia vegetal que não a da área de estudo.

De acordo com os atributos da espécie e observações de campo, as exóticas foram classificadas conforme o agrupamento proposto por Durigan et al. (2013) [2]: exóticas transientes, ruderais (dominantes e não dominantes) e invasoras (dominantes e não dominantes). Foram ferramentas úteis na busca dos atributos de cada espécie as informações disponíveis no banco de dados de espécies exóticas invasoras no Brasil [39] ou no compêndio de espécies exóticas invasoras [40].

As espécies nativas dos componentes transiente e residente foram distribuídas em grupos funcionais de polinização, dispersão e sucessão. Para classificação das síndromes de polinização e dispersão foram utilizados dados presentes na literatura com base nas características 
morfológicas e ecológicas das espécies [41, 42]. Na ausência de informação no nível de espécie, considerou-se o gênero e/ou a família como base para definição da síndrome. As espécies foram classificadas em três síndromes: zoofilia, anemofilia e autopolinização. Para classificação do tipo de dispersão foram adotados três grupos (anemocóricas, zoocóricas e autocóricas) [43]. As categorias sucessionais de cada espécie foram obtidas por meio de busca bibliográfica e seguiram o conceito apresentado por Brancalion et al. (2015) [14]: pioneiras (P), secundárias (S), clímaces de dossel $(\mathrm{Cd})$ e clímaces de subosque $(\mathrm{Cs})$. As espécies exóticas foram classificadas somente quanto às síndromes de polinização e dispersão, pois categorias sucessionais não se aplicam para esse grupo.

Dentre as espécies registradas, foram evidenciadas aquelas ameaçadas de extinção com base nas listas oficiais do estado de São Paulo [44], do Brasil [45, 46] e/ou do mundo [47]. A listagem de espécies do componente transiente do estrato regenerante foi comparada à do estrato adulto obtido para a mesma área [23], a fim de verificar eventuais alterações na proporção de grupos funcionais entre estratos.

\subsection{Análise dos dados}

Os parâmetros fitossociológicos calculados para o componente transiente foram aqueles destacados em Martins (1991) [48] e também utilizados em Souza et al. (2016) [23], obtidos por meio do programa FITOPAC 2.1 [49]. Para as populações do componente residente, o valor de importância (VI) foi determinado substituindo a dominância relativa pelo índice de cobertura [50], em que foi considerada como unidade amostral a parcela de $10 \mathrm{~m}^{2}$, que constitui na somatória dos dados de cobertura por espécie (valores da escala de Braun-Blanquet) nas 10 subparcelas circulares de $1 \mathrm{~m}^{2}$. Os grupos funcionais relacionados às síndromes de polinização, dispersão e sucessão foram obtidos para os componentes residente e transiente, por meio de contagem de indivíduos ou de espécies de mesma categoria. Para esse agrupamento foi utilizada a classificação das espécies em grupos funcionais detalhada em Manfra et al. (2018) [51].

\section{RESULTADOS}

Foram amostrados 1.150 indivíduos regenerantes vivos (5 indivíduos $\left.\mathrm{m}^{-2}\right)$, distribuídos em 114 espécies (Tabela 1). Considerando somente aquelas com binômio completo, foram identificadas 93 espécies, pertencentes a 79 gêneros e 48 famílias, das quais $25 \%$ espécies exóticas (Tabelas 2 e 3). Embora nativas no Brasil, Chrysophyllum gonocarpum, Dalbergia nigra, Esenbeckia leiocarpa, Holocalyx balansae e Poincianella pluviosa não apresentam registros de ocorrência natural para a Serra da Cantareira, sendo caracterizadas como exóticas no PEAL.

Tabela 1: Descritores do estrato regenerante de vegetação secundária de Floresta Ombrófila Densa no Parque Estadual Alberto Löfgren, São Paulo - SP.

\begin{tabular}{lrrrrr}
\hline Descritores & \multicolumn{2}{c}{ Indivíduos } & & \multicolumn{2}{c}{ Espécies } \\
\cline { 2 - 3 } \cline { 5 - 6 } & $N^{\circ}$ & $\%$ & & $N^{\circ}$ & $\%$ \\
\hline Comunidade total & $\mathbf{1 . 1 5 0}$ & $\mathbf{1 0 0}$ & & $\mathbf{1 1 4}$ & $\mathbf{1 0 0}$ \\
Nativas & 666 & 58 & & 72 & 63 \\
Exóticas & 460 & 40 & & 27 & 24 \\
Não classificadas & 24 & 2 & & 15 & 13 \\
Componente Transiente & $\mathbf{8 2 2}$ & $\mathbf{1 0 0}$ & & $\mathbf{7 3}$ & $\mathbf{1 0 0}$ \\
Nativas & 596 & 72 & & 57 & 78 \\
Exóticas & 226 & 27 & & 16 & 21 \\
Componente Residente & $\mathbf{3 0 4}$ & $\mathbf{1 0 0}$ & & $\mathbf{2 6}$ & $\mathbf{1 0 0}$ \\
Nativas & 70 & 23 & & 17 & 65 \\
Exóticas & 234 & 77 & & 9 & 35 \\
\hline
\end{tabular}

Espécies ameaçadas de extinção foram registradas somente no componente transiente (Tabela 2). Duas espécies nativas foram consideradas vulneráveis à extinção: Euterpe edulis, presente na lista paulista e nacional de espécies ameaçadas e Nectandra barbellata, na lista nacional e global. 
Embora exóticas na Floresta Ombrófila Densa da Serra da Cantareira, outras três espécies também constam como ameaçadas de extinção: Aspidosperma polyneuron, em perigo de extinção em escala global, Esenbeckia leiocarpa, considerada vulnerável à extinção em escala global e Dalbergia nigra, em perigo de extinção em São Paulo e vulnerável à extinção em escala nacional e global.

Tabela 2: Parâmetros fitossociológicos das espécies do componente transiente do estrato regenerante de vegetação secundária de Floresta Ombrófila Densa no Parque Estadual Alberto Löfgren, São Paulo - SP em ordem decrescente de Valor de Importância. $N=$ indivíduos $\left(n^{\circ}\right), D A=$ densidade absoluta (ind $\left.m^{-2}\right)$,

$D o A=$ dominância absoluta $\left(\mathrm{cm}^{2} \mathrm{~m}^{-2}\right), D o R=$ dominância relativa $(\%), D R=$ densidade relativa $(\%)$,

$F R=$ frequência relativa $(\%), V I=$ valor de importância, $V C=$ valor de cobertura. $(*)$ espécie exótica,

(^) ameaçada de extinção: SP = escala estadual (Mamede et al. 2007), BR = escala nacional (Brasil, 2014), $G L=$ escala global $(I U C N, 2015), V U=$ vulnerável, $E N=$ em perigo.

\begin{tabular}{|c|c|c|c|c|c|c|c|c|}
\hline Espécies & $\mathbf{N}$ & DA & DoA & DoR & DR & FR & VI & VC \\
\hline Myrcia splendens (Sw.) DC. & 190 & 0,86 & 0,40 & 7,13 & 23,11 & 6,71 & 36,96 & 30,25 \\
\hline $\begin{array}{l}\text { Archontophoenix cunninghamiana (H.Wendl.) } \\
\text { H.Wendl. e Drude* }\end{array}$ & 36 & 0,16 & 0,90 & 17,92 & 4,38 & 3,53 & 25,83 & 22,3 \\
\hline Pittosporum undulatum Vent.* & 75 & 0,34 & 0,60 & 11,15 & 9,12 & 4,95 & 25,23 & 20,28 \\
\hline Guarea macrophylla Vahl & 28 & 0,13 & 0,30 & 6,32 & 3,41 & 4,95 & 14,68 & 9,73 \\
\hline Nectandra barbellata Coe-Teixeira $\mathbf{\Delta V U}(\mathrm{BR}, \mathrm{GL})$ & 47 & 0,21 & 0,10 & 2,19 & 5,72 & 3,53 & 11,45 & 7,91 \\
\hline Paullinia seminuda Radlk. & 43 & 0,20 & 0,10 & 1,36 & 5,23 & 4,24 & 10,83 & 6,59 \\
\hline Syzygium jambos (L.) Alston* & 24 & 0,11 & 0,20 & 4,25 & 2,92 & 3,18 & 10,35 & 7,17 \\
\hline Toxicodendron vernicifluum (Stokes) F.A. Barkley* & 20 & 0,09 & 0,30 & 5,55 & 2,43 & 1,77 & 9,75 & 7,98 \\
\hline Livistona chinensis (Jacq.) R.Br. ex Mart.* & 11 & 0,05 & 0,30 & 5,13 & 1,34 & 2,47 & 8,94 & 6,47 \\
\hline Eugenia uniflora $\mathrm{L}$. & 28 & 0,13 & 0,00 & 0,85 & 3,41 & 3,89 & 8,15 & 4,26 \\
\hline Dendropanax cuneatus (DC.) Decne. \& Planch. & 19 & 0,09 & 0,10 & 2,84 & 2,31 & 2,83 & 7,98 & 5,15 \\
\hline Cupania oblongifolia Mart. & 13 & 0,06 & 0,20 & 3,01 & 1,58 & 2,83 & 7,42 & 4,6 \\
\hline Piptadenia gonoacantha (Mart.) J.F. & 29 & 0,13 & 0,10 & 1,06 & 3,53 & 2,83 & 7,41 & 4,59 \\
\hline $\begin{array}{l}\text { Dalbergia nigra (Vell.) Allemão ex Benth.* }{ }^{*} \mathrm{EN}(\mathrm{SP}) \text {, } \\
\mathrm{VU}(\mathrm{BR}, \mathrm{GL})\end{array}$ & 15 & 0,07 & 0,10 & 1,89 & 1,82 & 2,83 & 6,54 & 3,71 \\
\hline Cupania vernalis Cambess. & 17 & 0,08 & 0,10 & 1,08 & 2,07 & 3,18 & 6,33 & 3,15 \\
\hline Piper aduncum $\mathrm{L}$. & 13 & 0,06 & 0,10 & 1,63 & 1,58 & 2,12 & 5,33 & 3,21 \\
\hline Psychotria carthagenensis Jacq. & 12 & 0,05 & 0,00 & 0,56 & 1,46 & 3,18 & 5,2 & 2,02 \\
\hline Miconia cabucu Hoehne & 10 & 0,05 & 0,10 & 1,49 & 1,22 & 2,47 & 5,18 & 2,71 \\
\hline Metrodorea nigra A.St.-Hil. & 8 & 0,04 & 0,20 & 3,41 & 0,97 & 0,71 & 5,09 & 4,38 \\
\hline Syagrus romanzoffiana (Cham.) Glassman & 3 & 0,01 & 0,20 & 3,6 & 0,36 & 1,06 & 5,03 & 3,97 \\
\hline Cabralea canjerana (Vell.) Mart. & 8 & 0,04 & 0,10 & 2,01 & 0,97 & 1,41 & 4,39 & 2,98 \\
\hline Tibouchina sellowiana Cogn. & 17 & 0,08 & 0,00 & 0,12 & 2,07 & 1,06 & 3,25 & 2,19 \\
\hline Holocalyx balansae Micheli* & 9 & 0,04 & 0,00 & 0,72 & 1,09 & 1,41 & 3,23 & 1,82 \\
\hline Esenbeckia febrifuga (A.St.-Hil.) A. Juss. ex Mart. & 6 & 0,03 & 0,10 & 2,03 & 0,73 & 0,35 & 3,11 & 2,76 \\
\hline Psychotria suterella Müll.Arg. & 7 & 0,03 & 0,00 & 0,1 & 0,85 & 2,12 & 3,07 & 0,95 \\
\hline Melia azedarach L.* & 10 & 0,05 & 0,00 & 0,14 & 1,22 & 1,41 & 2,77 & 1,36 \\
\hline Matayba guianensis Aubl. & 6 & 0,03 & 0,00 & 0,53 & 0,73 & 1,41 & 2,67 & 1,26 \\
\hline Casearia sylvestris $\mathrm{Sw}$. & 3 & 0,01 & 0,10 & 1,58 & 0,36 & 0,71 & 2,66 & 1,95 \\
\hline Aspidosperma polyneuron Müll.Arg.* $\mathbf{\Delta} \mathrm{EN}(\mathrm{GL})$ & 9 & 0,04 & 0,00 & 0,42 & 1,09 & 1,06 & 2,58 & 1,52 \\
\hline Pera glabrata (Schott) Poepp. ex Baill. & 3 & 0,01 & 0,10 & 1,05 & 0,36 & 1,06 & 2,47 & 1,41 \\
\hline Centrolobium tomentosum Guillem. ex Benth. & 6 & 0,03 & 0,00 & 0,31 & 0,73 & 1,41 & 2,45 & 1,04 \\
\hline Psychotria vellosiana Benth. & 5 & 0,02 & 0,00 & 0,26 & 0,61 & 1,41 & 2,28 & 0,87 \\
\hline Esenbeckia leiocarpa Engl. $* \mathbf{\Delta} \mathrm{VU}(\mathrm{GL})$ & 5 & 0,02 & 0,00 & 0,54 & 0,61 & 1,06 & 2,21 & 1,15 \\
\hline
\end{tabular}




\begin{tabular}{|c|c|c|c|c|c|c|c|c|}
\hline Espécies & $\mathbf{N}$ & DA & DoA & DoR & DR & FR & VI & VC \\
\hline Inga vera Willd. & 6 & 0,03 & 0,00 & 0,06 & 0,73 & 1,41 & 2,21 & 0,79 \\
\hline $\begin{array}{l}\text { Allophylus edulis (A.St.-Hil. et al.) Hieron. ex } \\
\text { Niederl. }\end{array}$ & 5 & 0,02 & 0,00 & 0,35 & 0,61 & 1,06 & 2,02 & 0,96 \\
\hline 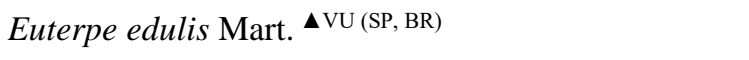 & 2 & 0,01 & 0,00 & 0,99 & 0,24 & 0,71 & 1,94 & 1,24 \\
\hline Pterocarpus rohrii Vahl & 1 & 0,00 & 0,10 & 1,45 & 0,12 & 0,35 & 1,93 & 1,57 \\
\hline Guapira opposita (Vell.) Reitz & 6 & 0,03 & 0,00 & 0,35 & 0,73 & 0,71 & 1,79 & 1,08 \\
\hline Myrciaria floribunda (H.West ex Willd.) O.Berg & 9 & 0,04 & 0,00 & 0,29 & 1,09 & 0,35 & 1,74 & 1,39 \\
\hline Myrsine coriacea (Sw.) R.Br. ex Roem. \& Schult. & 5 & 0,02 & 0,00 & 0,06 & 0,61 & 1,06 & 1,72 & 0,66 \\
\hline $\begin{array}{l}\text { Chrysophyllum gonocarpum (Mart. \& Eichler ex } \\
\text { Miq.) Engl.* }\end{array}$ & 3 & 0,01 & 0,00 & 0,58 & 0,36 & 0,71 & 1,65 & 0,95 \\
\hline Piptocarpha macropoda (DC.) Baker & 1 & 0,00 & 0,10 & 1,09 & 0,12 & 0,35 & 1,57 & 1,21 \\
\hline Eugenia pisiformis Cambess. & 3 & 0,01 & 0,00 & 0,1 & 0,36 & 1,06 & 1,52 & 0,46 \\
\hline Prunus myrtifolia (L.) Urb. & 3 & 0,01 & 0,00 & 0,04 & 0,36 & 1,06 & 1,47 & 0,41 \\
\hline Solanum pseudoquina A.St.-Hil. & 3 & 0,01 & 0,00 & 0,34 & 0,36 & 0,71 & 1,42 & 0,71 \\
\hline Poincianella pluviosa (DC.) L.P.Queiroz* & 4 & 0,02 & 0,00 & 0,21 & 0,49 & 0,71 & 1,4 & 0,7 \\
\hline Mollinedia schottiana (Spreng.) Perkins & 4 & 0,02 & 0,00 & 0,2 & 0,49 & 0,71 & 1,4 & 0,69 \\
\hline Handroanthus impetiginosus (Mart. ex DC.) Mattos & 2 & 0,01 & 0,00 & 0,42 & 0,24 & 0,71 & 1,37 & 0,66 \\
\hline Senegalia polyphylla (DC.) Britton \& Rose & 5 & 0,02 & 0,00 & 0,04 & 0,61 & 0,71 & 1,36 & 0,65 \\
\hline Psychotria nuda (Cham. \& Schltdl.) Wawra & 1 & 0,00 & 0,00 & 0,26 & 0,12 & 0,35 & 0,73 & 0,38 \\
\hline Sloanea guianensis (Aubl.) Benth. & 1 & 0,00 & 0,00 & 0,18 & 0,12 & 0,35 & 0,66 & 0,31 \\
\hline Malvaviscus arboreus Cav.* & 2 & 0,01 & 0,00 & 0,02 & 0,24 & 0,35 & 0,62 & 0,27 \\
\hline Eugenia acutata Miq. & 1 & 0,00 & 0,00 & 0,1 & 0,12 & 0,35 & 0,58 & 0,22 \\
\hline Monstera deliciosa Liebm.* & 1 & 0,00 & 0,00 & 0,1 & 0,12 & 0,35 & 0,58 & 0,22 \\
\hline Sessea brasiliensis Toledo & 1 & 0,00 & 0,00 & 0,1 & 0,12 & 0,35 & 0,58 & 0,22 \\
\hline Handroanthus ochraceus (Cham.) Mattos & 1 & 0,00 & 0,00 & 0,09 & 0,12 & 0,35 & 0,56 & 0,21 \\
\hline Eriobotrya japonica (Thunb.) Lindl.* & 1 & 0,00 & 0,00 & 0,07 & 0,12 & 0,35 & 0,55 & 0,19 \\
\hline Calophyllum brasiliense Cambess. & 1 & 0,00 & 0,00 & 0,05 & 0,12 & 0,35 & 0,52 & 0,17 \\
\hline Hovenia dulcis Thunb.* & 1 & 0,00 & 0,00 & 0,04 & 0,12 & 0,35 & 0,51 & 0,16 \\
\hline Symplocos falcata Brand & 1 & 0,00 & 0,00 & 0,04 & 0,12 & 0,35 & 0,51 & 0,16 \\
\hline Myrcia tomentosa (Aubl.) DC. & 1 & 0,00 & 0,00 & 0,03 & 0,12 & 0,35 & 0,5 & 0,15 \\
\hline Myrsine umbellata Mart. & 1 & 0,00 & 0,00 & 0,01 & 0,12 & 0,35 & 0,49 & 0,13 \\
\hline Tapirira guianensis Aubl. & 1 & 0,00 & 0,00 & 0,01 & 0,12 & 0,35 & 0,49 & 0,13 \\
\hline Amaioua intermedia Mart. Ex Schult. \& Schult.f. & 1 & 0,00 & 0,00 & 0,01 & 0,12 & 0,35 & 0,48 & 0,13 \\
\hline Cryptocarya saligna $\mathrm{Mez}$ & 1 & 0,00 & 0,00 & 0,01 & 0,12 & 0,35 & 0,48 & 0,13 \\
\hline Endlicheria paniculata (Spreng.) J.F.Macbr. & 1 & 0,00 & 0,00 & 0,01 & 0,12 & 0,35 & 0,48 & 0,13 \\
\hline Erythrina speciosa Andrews & 1 & 0,00 & 0,00 & 0,01 & 0,12 & 0,35 & 0,48 & 0,13 \\
\hline Ilex sp. & 1 & 0,00 & 0,00 & 0,01 & 0,12 & 0,35 & 0,48 & 0,13 \\
\hline Lacistema sp. & 1 & 0,00 & 0,00 & 0,00 & 0,12 & 0,35 & 0,48 & 0,12 \\
\hline Machaerium stipitatum Vogel & 1 & 0,00 & 0,00 & 0,00 & 0,12 & 0,35 & 0,48 & 0,12 \\
\hline Tetrorchidium rubrivenium Poepp. & 1 & 0,00 & 0,00 & 0,00 & 0,12 & 0,35 & 0,48 & 0,12 \\
\hline Parapiptadenia rigida (Benth.) Brenan & 1 & 0,00 & 0,00 & 0,00 & 0,12 & 0,35 & 0,48 & 0,12 \\
\hline Solanum swartzianum Roem. \& Schult. & 1 & 0,00 & 0,00 & 0,00 & 0,12 & 0,35 & 0,48 & 0,12 \\
\hline
\end{tabular}


Tabela 3: Parâmetros fitossociológicos das espécies do componente residente do estrato regenerante de vegetação secundária de Floresta Ombrófila Densa no Parque Estadual Alberto Löfgren, São Paulo - SP em ordem decrescente de VI. $N=$ indivíduos $\left(n^{\circ}\right), D A=$ densidade absoluta (ind $\left.m^{-2}\right), D R=$ densidade relativa (\%), $F R=$ frequência relativa (\%), $\Sigma C=$ Somatório da classe de cobertura por espécie, $C R=$ cobertura relativa (\%) e VI = valor de importância. $(*)$ espécie exótica.

\begin{tabular}{|c|c|c|c|c|c|c|c|}
\hline Espécies & $\mathbf{N}$ & DA & DR & FR & $\Sigma \mathrm{C}$ & CR & VI \\
\hline Coffea arabica $\mathrm{L} . *$ & 119,00 & 0,54 & 39,14 & 19,40 & 54,00 & 52,94 & 111,48 \\
\hline Petiveria alliacea $\mathrm{L} . *$ & 79,00 & 0,36 & 25,99 & 2,99 & 13,00 & 12,75 & 41,73 \\
\hline Heteropterys cf. intermedium A.Juss. & 20,00 & 0,09 & 6,58 & 11,94 & 7,00 & 6,86 & 25,38 \\
\hline Asparagus setaceus (Kunth) Jessop* & 14,00 & 0,06 & 4,61 & 2,99 & 12,00 & 11,76 & 19,36 \\
\hline Peltastes peltatus (Vell.) Woodson* & 15,00 & 0,07 & 4,93 & 13,43 & 0,00 & 0,00 & 18,36 \\
\hline Brunfelsia sp. & 13,00 & 0,06 & 4,28 & 2,99 & 8,00 & 7,84 & 15,11 \\
\hline Brunfelsia uniflora (Pohl) D.Don & 9,00 & 0,04 & 2,96 & 7,46 & 2,00 & 1,96 & 12,38 \\
\hline Erythroxylum pulchrum A.St.-Hil. & 4,00 & 0,02 & 1,32 & 5,97 & 0,00 & 0,00 & 7,29 \\
\hline Serjania caracasana (Jacq.) Willd. & 5,00 & 0,02 & 1,64 & 2,99 & 2,00 & 1,96 & 6,59 \\
\hline Piper lhotzkyanum Kunth & 2,00 & 0,01 & 0,66 & 2,99 & 2,00 & 1,96 & 5,61 \\
\hline Rhododendron simsii Planch* & 3,00 & 0,01 & 0,99 & 2,99 & 0,00 & 0,00 & 3,98 \\
\hline Thunbergia sp. & 4,00 & 0,02 & 1,32 & 1,49 & 1,00 & 0,98 & 3,79 \\
\hline Costus spiralis (Jacq.) Roscoe & 2,00 & 0,01 & 0,66 & 2,99 & 0,00 & 0,00 & 3,65 \\
\hline Nephrolepis sp.* & 1,00 & 0,00 & 0,33 & 1,49 & 1,00 & 0,98 & 2,80 \\
\hline Anemia phyllitidis (L.) Sw. & 2,00 & 0,01 & 0,66 & 1,49 & 0,00 & 0,00 & 2,15 \\
\hline Justicia carnea Lindl. & 2,00 & 0,01 & 0,66 & 1,49 & 0,00 & 0,00 & 2,15 \\
\hline Cynodon sp.* & 1,00 & 0,00 & 0,33 & 1,49 & 0,00 & 0,00 & 1,82 \\
\hline Ochna serrulata (Hochst.) Walp.* & 1,00 & 0,00 & 0,33 & 1,49 & 0,00 & 0,00 & 1,82 \\
\hline Thunbergia grandiflora Roxb.* & 1,00 & 0,00 & 0,33 & 1,49 & 0,00 & 0,00 & 1,82 \\
\hline cf. Solidago chilensis Meyen & 1,00 & 0,00 & 0,33 & 1,49 & 0,00 & 0,00 & 1,82 \\
\hline $\begin{array}{l}\text { Cordiera myrciifolia (K.Schum.) C.H.Perss. } \\
\text { \& Delprete }\end{array}$ & 1,00 & 0,00 & 0,33 & 1,49 & 0,00 & 0,00 & 1,82 \\
\hline Maytenus evonymoides Reissek & 1,00 & 0,00 & 0,33 & 1,49 & 0,00 & 0,00 & 1,82 \\
\hline Pfaffia glomerata (Spreng.) Pedersen & 1,00 & 0,00 & 0,33 & 1,49 & 0,00 & 0,00 & 1,82 \\
\hline Piper arboreum Aubl. & 1,00 & 0,00 & 0,33 & 1,49 & 0,00 & 0,00 & 1,82 \\
\hline Tripogandra diuretica (Mart.) Handlos & 1,00 & 0,00 & 0,33 & 1,49 & 0,00 & 0,00 & 1,82 \\
\hline Urera nitida (Vell.) P.Brack & 1,00 & 0,00 & 0,33 & 1,49 & 0,00 & 0,00 & 1,82 \\
\hline
\end{tabular}

Predominaram espécies de árvores (60\%), seguidas pelos arbustos (11\%), ervas (6\%), trepadeiras (4\%), palmeiras (3\%) e hemiepífitas (1\%). As morfoespécies, das quais não foi possível a determinação do hábito de crescimento, corresponderam a $15 \%$ da riqueza. A maior parte das espécies do estrato regenerante, considerando os componentes residente e transiente, são polinizadas $(97 \%)$ e dispersas $(70 \%)$ por animais. O vento é o agente polinizador para $3 \%$ e dispersor para $17 \%$ das espécies. A autocoria prevalece em $13 \%$ das espécies.

Componente transiente - composto por 822 indivíduos (densidade total de 4 indivíduos $\mathrm{m}^{-2} \mathrm{e}$ área basal total de $5 \mathrm{~cm}^{2} \mathrm{~m}^{-2}$ ), distribuídos em 73 espécies, 62 gêneros e 33 famílias (Tabela 2). Indivíduos jovens de árvores predominaram nesse componente (89\%), seguido pelas palmeiras $(5 \%)$, arbustos (4\%), trepadeiras (1\%) e hemiepífitas (1\%). O índice de diversidade de Shannon (H') obtido foi de 3,289 e a equabilidade 0,767 .

As nativas somaram 596 indivíduos (72\%), distribuídas em 57 espécies (78\%). A importância da fauna para a comunidade regenerante se mantém quando consideradas a abundância de plantas e a riqueza de espécies do estrato regenerante transiente comparado ao componente adulto (Figura 
2). As proporções entre as categorias de cada síndrome nos dois estratos também foram similares, exceto para anemocóricas, com maior proporção em riqueza e abundância relativa no componente adulto comparado ao transiente. A maior parte das nativas foi distribuída entre espécies secundárias ou clímax de dossel (Figuras 3C e 3D). Comparado ao componente adulto, o estrato regenerante apresentou menor riqueza e abundância de pioneiras e secundárias e aumento em espécies climax de subosque (Figuras 3C e 3D).

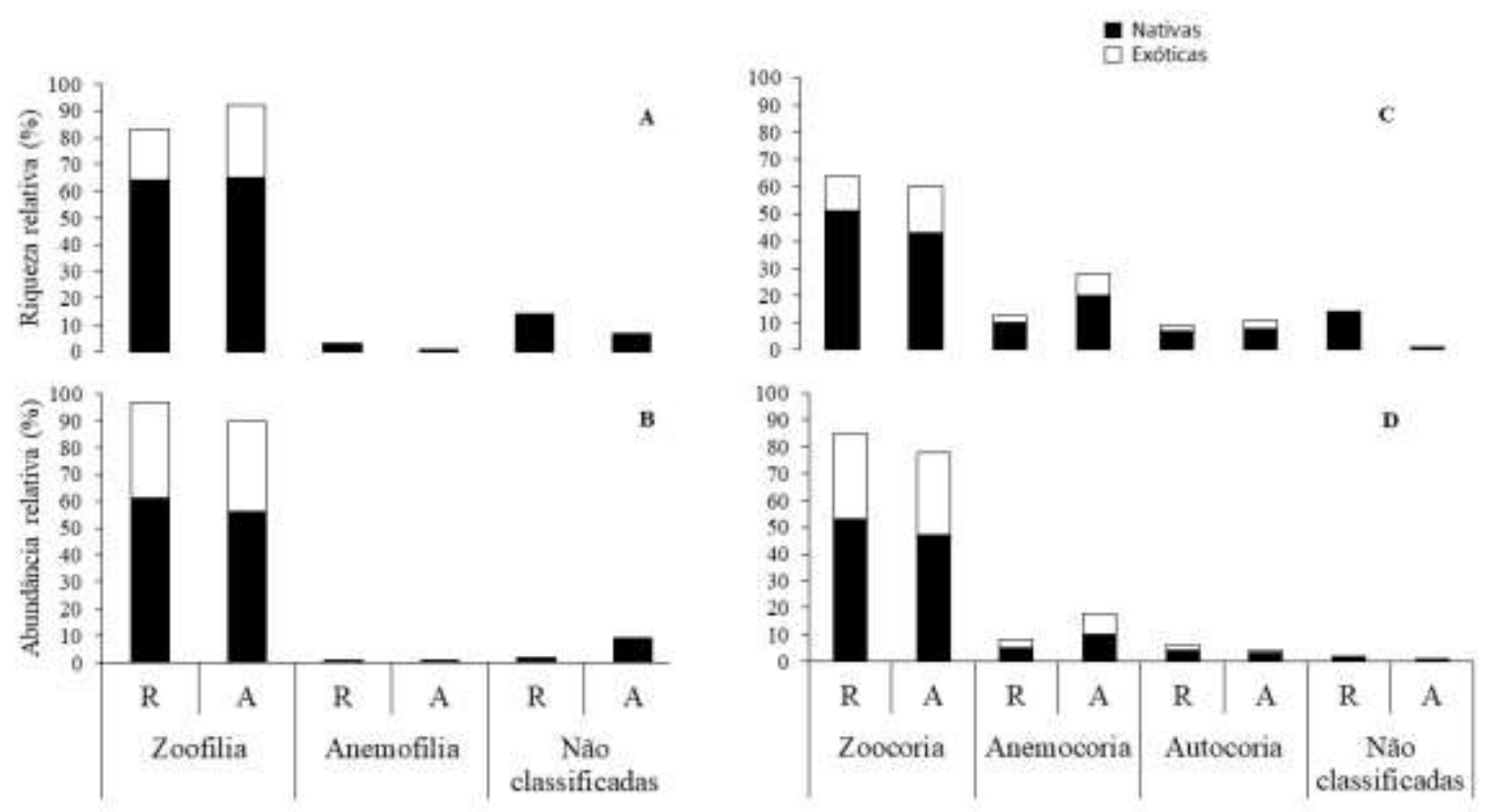

Figura 2: Riqueza e abundância relativa de espécies nativas e exóticas conforme síndromes de polinização $(A$ e $B)$ e dispersão $(C$ e $D)$ de espécies do estrato regenerante transiente $(R)$ e do componente adulto (A) em vegetação secundária de Floresta Ombrófila Densa no Parque Estadual Alberto Löfgren, São Paulo - SP.

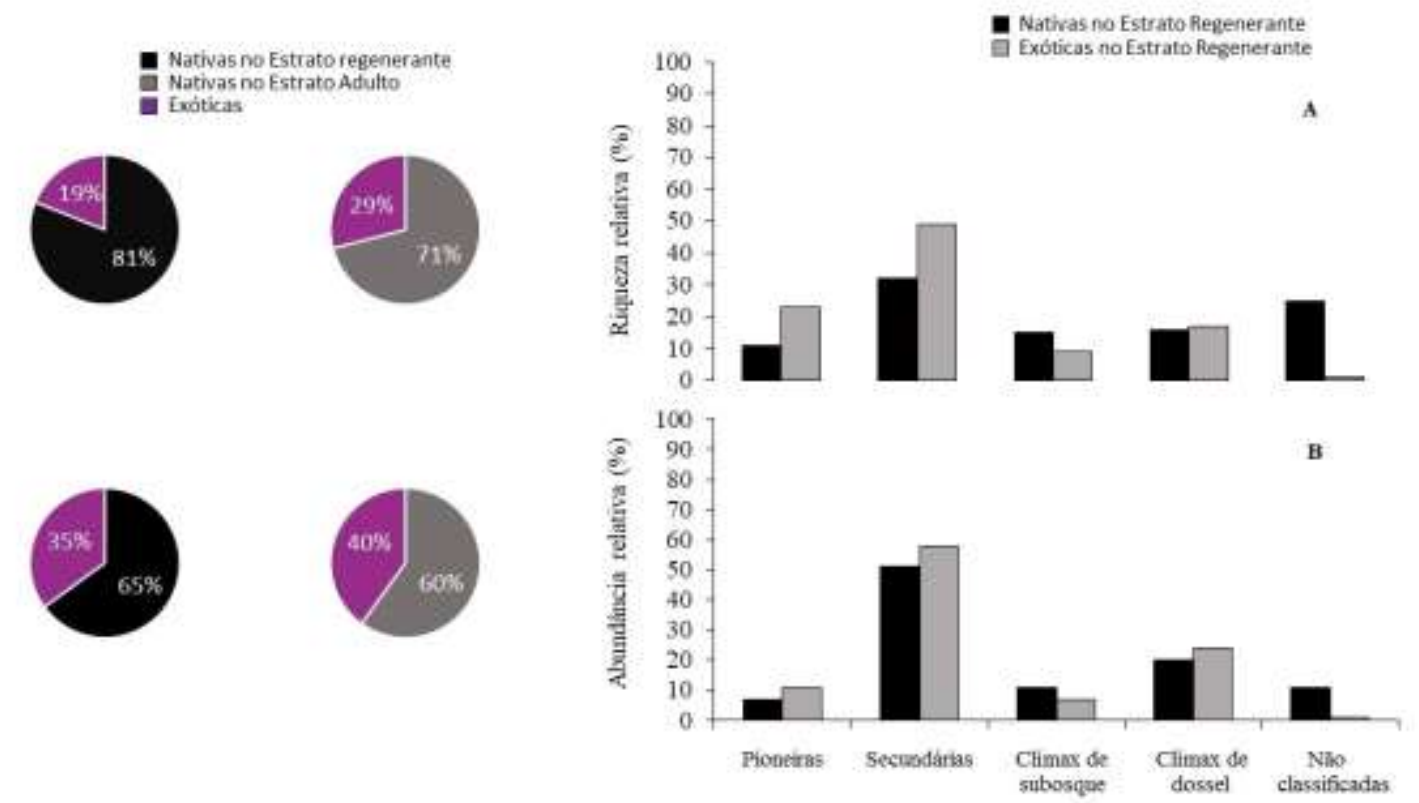

Figura 3: Proporção de espécies exóticas em relação às nativas no estrato regenerante e adulto (Ariqueza e $B$ - número de indivíduos) e distribuição das espécies nativas em grupos sucessionais no estrato regenerante e adulto $(C$ - riqueza e $D$-número de indivíduos) em vegetação secundária de Floresta Ombrófila Densa no Parque Estadual Alberto Löfgren, São Paulo - SP. 
As exóticas somaram 226 indivíduos (27\%) e 16 espécies (21\%), e assim como as nativas em sua maioria polinizadas e dispersas por animais (Figura 2). Desta riqueza total, 57\% foram consideradas espécies invasoras não dominantes e $43 \%$ invasoras dominantes. Cinco destas invasoras dominantes se destacaram entre os dez maiores valores de importância (VI) na comunidade: Archontophoenix cunninghamiana, Pittosporum undulatum, Syzygium jambos, Toxicodendron vernicifluum e Livistona chinensis (Figura 4, Tabela 2).

Embora mantenham posição de destaque na estrutura da comunidade regenerante, houve diminuição de exóticas em termos de riqueza de espécies e abundância de indivíduos quando comparada à proporção observada no estrato adulto (Figura 3A e 3B).

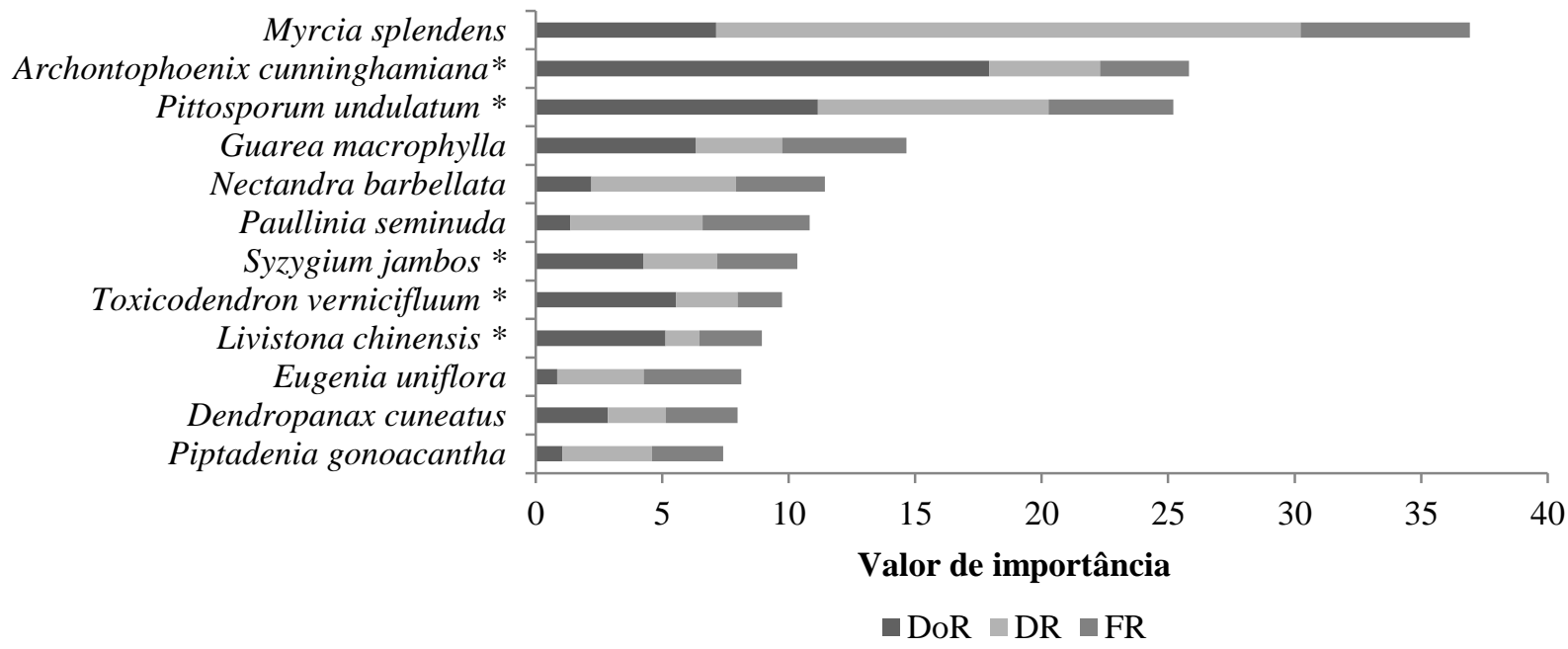

Figura 4: Espécies de maior valor de importância do estrato transiente da flora regenerante do Parque Estadual Alberto Löfgren, São Paulo - SP. (*) espécie exótica.

Componente residente - foram registrados 304 indivíduos ( 1 indivíduo $\mathrm{m}^{-2}$ ), distribuídos em 26 espécies, 23 gêneros e 21 famílias (Tabela 3). Os arbustos predominaram (43\%), seguido pelas ervas (30\%), trepadeiras (17\%) e árvores de pequeno porte (9\%). Este componente apresentou índice de diversidade de Shannon (H') de 1,992 e equabilidade 0,61.

As nativas somaram 70 indivíduos (23\%), distribuídas em 17 espécies (65\%). Todas as plantas deste componente apresentaram polinização por animais; dentre as síndromes de dispersão, também predominou a zoocoria (56\%), seguido da anemocoria (25\%) e autocoria (19\%). Quanto aos grupos sucessionais, sete espécies nativas não foram classificadas (44\%), seis espécies foram consideradas clímax de subosque (37\%), duas pioneiras (12\%) e uma secundária (6\%). O percentual elevado de não classificadas deveu-se à ausência de informações na literatura sobre essas espécies.

As exóticas somaram 234 indivíduos (77\%), distribuídas em nove espécies (35\%), das quais $77 \%$ invasoras não dominantes e 33\% invasoras dominantes. Quatro dessas invasoras dominantes se destacaram entre as dez espécies com maior valor de importância: Coffea arabica, Petiveria alliacea, Asparagus setaceus e Peltastes peltatus (Figura 5, Tabela 3). 


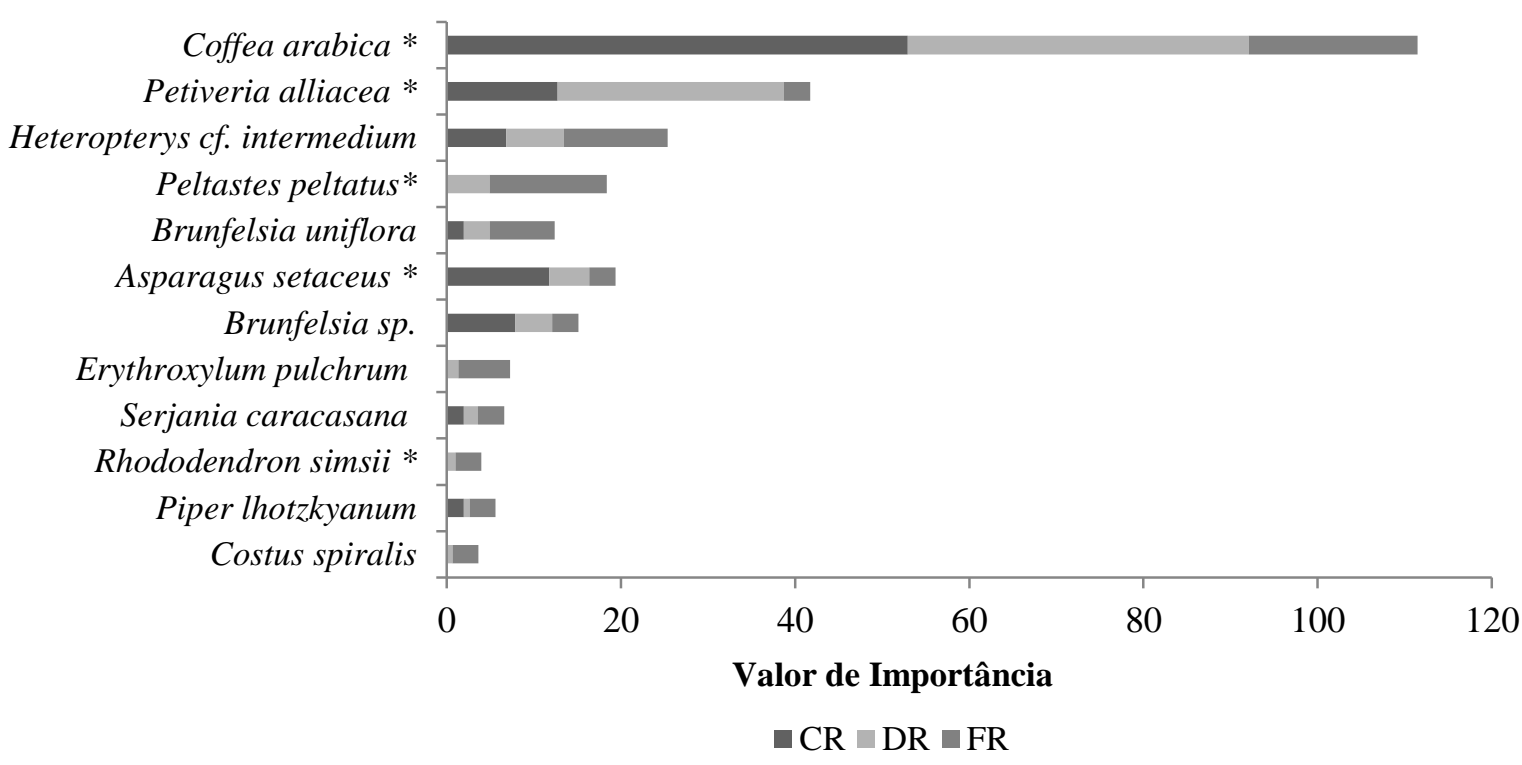

Figura 5: Espécies de maior valor de importância do estrato residente da flora regenerante do Parque Estadual Alberto Löfgren, São Paulo $-S P . C R=$ cobertura relativa, $D R=$ densidade relativa, $F R=$ frequência relativa, (*) espécie exótica.

\section{DISCUSSÃO}

Estudo prévio realizado em Floresta Ombrófila Densa no Parque Estadual Alberto Löfgren (PEAL) constatou que populações de plantas exóticas ocupavam altos valores de importância na comunidade arbórea, em um claro processo de invasão biológica [23]. Esta invasão teria origem nos distúrbios antrópicos frequentes no passado do PEAL, como o plantio de talhões de espécies exóticas e o descarte inapropriado de mudas e sementes, e pela sua proximidade de espaços urbanos onde são cultivadas espécies ornamentais. Por se tratar de vegetação secundária, o ambiente também seria mais suscetível à invasão por propágulos provenientes dessas áreas-fonte [21].

Com invasoras ocupando posição importante na comunidade arbórea, era prevista a presença das exóticas também na comunidade regenerante. Os resultados aqui apresentados corroboraram a presença das mesmas invasoras em destaque no componente adulto também no componente regenerante transiente, somada ao registro de novas espécies invasoras no residente. No entanto, parcela significativa de plantas nativas foram registradas no local, o que demonstra que ainda há certo grau de resistência do ambiente à invasão, mas que pode ser rompida caso a pressão de propágulos não seja controlada.

Como indicador positivo há o destaque de Fabaceae, Myrtaceae e Rubiaceae entre as de maior riqueza no estrato regenerante transiente. Estas famílias também figuram entre as de maior riqueza na comunidade arbórea da Floresta Atlântica de encosta do estado de São Paulo [50]. Portanto, ao menos no nível de família, a vegetação secundária do PEAL está recuperando a sua composição florística conforme o esperado.

Outro indicador positivo é a presença de espécies ameaçadas de extinção, indício de que essas populações estão conseguindo se reproduzir localmente. Euterpe edulis e Nectandra barbellata são nativas da Floresta Ombrófila Densa da Serra da Cantareira. No entanto, Aspidosperma polyneuron e Dalbergia nigra são exóticas e só se estabeleceram no PEAL porque foram cultivadas para fins experimentais nos arboretos. Embora presentes no estrato regenerante, não há indícios de que venham a se tornar invasoras dominantes na comunidade, mas o monitoramento é recomendado [2]. Por outro lado, a capacidade de se estabelecer no estrato regenerante de florestas secundárias indica que é possível recuperar essas populações em sua distribuição geográfica natural, desde que sejam elaborados planos de ação visando o enriquecimento de remanescentes florestais com essas espécies. Como ambas apresentam valor madeireiro, motivo 
pelo qual foram muito exploradas no passado, também são indicadas para projetos de manejo sustentável em áreas de reserva legal.

Com relação aos grupos funcionais, a polinização por animais foi predominante entre as espécies (acima de 80\%), tanto no estrato regenerante transiente quanto no adulto. O resultado encontra-se próximo ao padrão descrito por Bawa (1990) [52], o qual estimou que $90 \%$ das espécies das florestas tropicais apresentam esta síndrome.

Quanto à dispersão, também predominaram espécies zoocóricas no estrato regenerante transiente e adulto, com valores acima de $60 \%$. O percentual de zoocoria só não foi mais elevado devido à alta proporção de espécies anemocóricas e autocóricas no dossel, ainda ocupado em grande parte por pioneiras e secundárias no componente adulto. A associação entre o aumento da proporção de espécies zoocóricas com o desenvolvimento estrutural foi observada em vários estudos para a Floresta Atlântica, mesmo em diferentes fisionomias [53, 54, 55, 56]; entretanto, ainda não há consenso entre os estudos sobre a porcentagem esperada de zoocoria em florestas maduras. De acordo com Liebsch et al. (2008) [55], cerca de 80\% da comunidade vegetal presente na Mata Atlântica apresenta síndrome de dispersão por animais, mas outros estudos reportam que o percentual de espécies zoocóricas varia de $60 \%$ a $90 \%$ [57].

Embora a proporção de espécies polinizadas ou dispersas por animais seja semelhante à encontrada em florestas maduras, um indicador negativo e preocupante é o fato das exóticas ocuparem mais de $10 \%$ da riqueza e mais de $20 \%$ dos indíviduos desses grupos funcionais: o processo de invasão biológica pode aumentar, com o agravante de comprometer a sucessão natural, considerando que essas exóticas invasoras já estabeleceram relações com a fauna polinizadora e dispersora local $[58,59,60]$.

A análise dos grupos sucessionais também contribuiu com indicadores positivos, pois constatou-se que a floresta apresenta potencial de regeneração natural: espera-se que ocorra diminuição das espécies pioneiras e secundárias iniciais ao longo do tempo, cedendo espaço ao desenvolvimento de espécies não pioneiras e de subosque [55]. Assim, embora no componente adulto tenha sido observado alto percentual de espécies pioneiras e secundárias iniciais (72\%), com valores de densidade de indivíduos semelhantes entre essas categorias [23], espécies pioneiras típicas, como as do gênero Alchornea, ocupam os maiores valores de importância no dossel, mas não foram amostradas no estrato regenerante. Portanto, as condições atuais no subosque são desfavoráveis para espécies pioneiras - que possuem como estratégia a formação de banco de sementes, e favoráveis às espécies finais de sucessão - que investem na composição de banco de plântulas [61].

O avanço sucessional da floresta pode resultar em maior resistência do ambiente à invasividade de algumas plantas exóticas. Como exemplo, Pinus spp. e Hovenia dulcis Humb. constam entre as de maior valor de importância no componente adulto [23], mas não apresentaram o mesmo destaque entre as regenerantes transientes. Já Archontophoenix cunninghamiana, Pittosporum undulatum e Toxicodendron vernicifluum possuem populações estruturadas no estrato arbóreo adulto e mantiveram valor em importância no estrato regenenerante transiente, além de se propagar com sucesso pela floresta do PEAL, pois possuem frutos atrativos para dispersores [23, 58]. Portanto, recomenda-se que essas espécies sejam alvos preferenciais para ações de manejo, a fim de diminuir a pressão de propágulos.

Archontophoenix cunninghamiana, popularmente conhecida como "palmeira-australiana" ou "seafórtia" e Pittosporum undulatum, conhecido como pau-incenso, têm origem australiana e foram introduzidas no Brasil para uso ornamental. Toxicodendron vernicifluum tem origem asiática; denominada de charão, foi introduzida em arboretos do PEAL a fim de fornecer insumo para a "Escola de Charão", que funcionou até 1972, com o intuito de ensinar a técnica de envernizar objetos utilizando a seiva natural da árvore (laca-japonesa). Essas três espécies são encontradas invadindo fragmentos florestais por vários estados brasileiros e até em outros países [62].

Com relação ao componente regenerante residente, nesse estrato as exóticas apresentaram percentuais superiores ao do transiente em termos de riqueza e número de indivíduos, indício de menor resiliência à invasão. Estabelecidas nesse estrato, além de competirem com as nativas residentes, as exóticas também dificultam ou impedem o estabelecimento das nativas transientes. Dessa forma, em áreas perturbadas, as exóticas residentes são capazes de estagnar a sucessão, ao 
compor uma cobertura vegetal capaz de excluir competitivamente as nativas [63]. Dentre as invasoras do estrato regenerante residente, são prioritárias para o manejo Coffea arabica e Petiveria alliacea.

Coffea arabica foi a espécie de maior valor de importância no componente regenerante residente. Antes da criação do Parque, em 1986, existiam nessa área e no entorno fazendas de café. Como espécie típica de subosque, o cafeeiro não compete com as nativas por espaço no dossel; entretanto, pode atuar como barreira para o desenvolvimento destas em estágios jovens, competindo por espaço e nutrientes [62]. Outros estudos também apontam que o café pode vir a ser um problema no subosque e sugerem ações de manejo [64]. Petiveria alliacea, somada ao cafeeiro, ocupou mais de $50 \%$ do valor de importância da comunidade residente. Trata-se de subarbusto perene conhecido como guiné, nativo da floresta amazônica e das áreas tropicais da América do Sul, Central, Caribe e África [31]. A planta é muito utilizada para fins religiosos e medicinais, portanto sua introdução no PEAL pode estar relacionada ao passado rural ou à presente proximidade com áreas urbanas [65]. Comum no subosque, mas também encontrada em clareiras [66], possui alto potencial alelopático [67], podendo impedir o estabelecimento de outras espécies.

Em resumo, a avaliação do estrato de regeneração da vegetação secundária do PEAL permitiu o diagnóstico de grave processo de invasão biológica: tanto o componente transiente quanto o componente residente apresentaram composição de espécies e estrutura da comunidade distintas do ecossistema de referência, no caso a vegetação natural de Floresta Ombrófila Densa desta região próxima à Serra da Cantareira [29]. As invasoras mais abundantes já estabeleceram relações com a fauna polinizadora e dispersora local, competindo por recursos com a comunidade nativa. Embora o estrato regenerante transiente apresente rico banco de plântulas e jovens de nativas finais de sucessão, o que pode aumentar a sua resiliência, algumas populações de invasoras ainda se estabelecem com sucesso. $\mathrm{O}$ estrato regenerante residente apresenta grau de invasão mais severo, também com recomendações de manejo.

A introdução de plantas exóticas foi uma consequência da ação humana, deliberada ou inadvertida, mas atualmente algumas populações são claramente invasoras, pois já não dependem de intervenção humana contínua para sua manutenção no ecossistema. A dinâmica de invasão é determinada até certo ponto pelo transporte de propágulos e movimento de organismos pela paisagem e, por sua vez, o ecossistema pode atuar como fonte de propágulos para áreas ainda preservadas. Nesse cenário, plantas invasoras no PEAL representam séria ameaça para invasões biológicas de outras áreas protegidas no entorno, como o Parque Estadual da Serra da Cantareira. Portanto, recomenda-se o manejo das populações aqui consideradas prioritárias, principalmente para diminuir a pressão de propágulos, criando condições para o aumento da resiliência do ecossistema.

No entanto, técnicas de manejo de plantas invasoras inseridas em um ambiente natural ainda são incipientes e, na maioria dos casos, particularizadas de acordo com a espécie. Sabe-se que as invasoras podem impedir o crescimento e a regeneração de espécies nativas pela competição ou por causar mudanças no ambiente local ou no funcionamento do ecossistema, alterações que podem permanecer mesmo se as espécies exóticas forem removidas [7]. Há também casos em que a remoção dos invasores-alvo permite que outras espécies exóticas se estabeleçam e alterem ainda mais o ecossistema [4].

Nesse cenário é preciso maior atenção aos ecossistemas que apresentam comunidades persistentes de exóticas invasoras, para os quais a erradicação total parece ser praticamente impossível, aproximando-as do conceito de neoecossistemas [3, 9]. No caso do PEAL, a erradicação de exóticas no componente adulto e regenerante transiente parece ser uma tarefa menos árdua do que o controle daquelas muito abundantes no componente regenerante residente, mas a definição das técnicas a serem empregadas deve prever e monitorar o efeito da supressão das invasoras sobre o banco de plântulas e sementes ali presente, a fim de evitar que o processo de invasão por uma ou mais espécies se torne cíclico. No entanto, o limiar que impede o sucesso de um projeto de restauração para ecossistemas invadidos muitas vezes não é apenas a sua viabilidade ecológica, mas o custo e a vontade política de se comprometer com tal custo [11]. 
Portanto, no caso do PEAL e de outras unidades de proteção integral, esforços devem ser empenhados pelo poder público e pela comunidade científica na busca de soluções que permitam a remoção das plantas invasoras, o estabelecimento da espécies nativas e dos processos ecológicos que garantam a autosustentabilidade dos ecossistemas e das populações ameaçadas ali existentes. Por esse motivo, este estudo baseou-se na instalação de parcelas permanentes, as quais serão alvo de experimentos de técnicas supressão de plantas invasoras, com avaliação periódica de indicadores da composição, estrutura e grupos funcionais da comunidade. Somente após a avaliação das técnicas empregadas será possível definir se essa floresta se inclinará à uma alteração progressiva, tendo por base o diagnóstico atual do estrato regenerante como referência.

$\mathrm{O}$ enquadramento da área de estudo num neoecossistema ou num ecossistema híbrido dependerá da resposta da comunidade às técnicas de manejo adaptativo a serem empregadas, pois ainda não está claro se será possível ou não a erradicação total das espécies invasoras. Ainda há incertezas sobre possíveis redundâncias funcionais entre plantas exóticas e nativas, portanto é preciso investigar se o manejo a ser aplicado será benéfico ou prejudicial até mesmo para a fauna ali presente, embora estudos prévios já indiquem que populações de avifauna podem ser favorecidas [58].

Certo grau de pragmatismo também é necessário nas decisões sobre o controle de plantas invasoras. Como a constatação de limiares irreversíveis não é um diagnóstico simples, Miller \& Bestelmeyer (2016) [3] argumentam que a caracterização dos ecossistemas conforme um gradiente de alteração já é bastante útil, sem a necessidade de distinção entre ecossistemas híbridos e neoecossistemas.

Por fim, é importante considerar que a restauração ecológica dos ecossistemas naturais em unidades de proteção integral, com erradicação de espécies exóticas invasoras, é um compromisso assumido perante tratados nacionais e internacionais $[68,69]$. No entanto, para áreas protegidas imersas em paisagens muito antropizadas, como áreas metropolitanas, poucos ecossistemas permanecerão livres de impactos humanos [70].

\section{AGRADECIMENTOS}

Ao CNPq e ao Programa de Iniciação Científica - PIBIC-IF, por conceder bolsa de Iniciação Científica aos dois primeiros autores. Aos pesquisadores João Batista Baitello (Lauraceae) e Osny Tadeu de Aguiar (Myrtaceae) pelo auxílio na identificação dos materiais botânicos.

\section{REFERÊNCIAS BIBLIOGRÁFICAS}

1. Mack RN, Simberloff D, Lonsdale WM, Evans H, Clou, M, Bazzaz FA. Biotic invasions: causes, epidemiology, global consequences and control. Ecological Applications. 2000 Jun;10:689-710, doi.org/10.1890/1051-0761(2000)010[0689:BICEGC]2.0.CO;2

2. Durigan G, Ivanauskas NM, Zakia MJB, Abreu RCR. Control of Invasive Plants: ecological and socioeconomic criteria for the decision making process. Natureza \& Conservação. 2013 Jul;11(1):2330, dx.doi.org/10.4322/natcon.2013.003

3. Miller JR, Bestelmeyer BT. What's wrong with novel ecosystems, really? Restoration Ecology. 2016. May,24: 577-582, doi:10.1111/rec.12378

4. Zavaleta ES, Hobbs RJ, Mooney HA. Viewing invasive species removal in a whole-ecosystem context. Trends in Ecology and Evolution. 2001 Aug;16(8):454-459, doi.org/10.1016/S0169-5347(01)02194-2

5. Seastedt TR, Hobbs RJ, Suding KN. Management of novel ecosystems: are novel approaches required? Frontiers in Ecology and the Environment. 2008 Dec;6(10):547-553, dx.doi. org/10.1890/070046

6. Gardener MR, Trueman M, Buddenhagen C, Heleno R, Jäger H, Atkinson R, Tye A. A pragmatic approach to the management of plant invasions in Galapagos. In: Foxcroft LC, Pys ek P, Richardson DM, Genovesi P (Eds). Plant invasions in protected areas: patterns, problems and challenges. Switzerland: Dordrecht Springer; 2013. p. 349-374, doi:10.1007/978-94-007-7750-7_16

7. Hobbs RJ, Arico S, Aronson J., Baron JS, Bridgewater P., Cramer VA, Epstein PR, Ewel JJ, Klink CA, Lugo AE, Norton D, Ojima D, Richardson DM, Sanderson EW, Valladares F, Vila M, Zamora R, Zobel M. Novel ecosystems: theoretical and management aspects of the new ecological world order. Global Ecology and Biogeography. 2006 Jan;15:1-7, doi:10.1111/j.1466-822X.2006.00212.x

8. Hobbs RJ, Higgs E, Harris JA. Novel ecosystems: implications for conservation and restoration. Trends in Ecology \& Evolution. 2009 Nov;24(11):599-605, dx.doi.org/10.1016/j.tree.2009.05.012. 
9. Hobbs, RJ, Higgs ES, Harris JA. Novel ecosystems: concept or inconvenient reality? A response to Murcia et al. Trends in Ecology \& Evolution 2014 Dec;29(12):645-646. doi.org/10.1016/j.tree.2014.09.006

10. Finn, Hugh \& Stock, William \& Valentine, Leonie. (2019). Pines and the ecology of Carnaby`s BlackCockatoos (Calyptorhynchus latirostris) in the Gnangara Sustainability Strategy Area. ECU Publications.

11. Murcia C, Aronson J, Kattan GH, Moreno-Mateos D, Dixon K, Simberloff D. A critique of the novel ecosystem concept. Trends Ecology \& Evolution. 2014 Oct;29(10): 548-53, doi: 10.1016/j.tree.2014.07.006

12. Milton SJ. Emerging ecosystem: A washig-stone for ecologists economist and sociologist? South African Journal of Science. 2003 Sep;99(9-10):404-406.

13. Hobbs RJ, Higgs ES, Hall C.M. Defining novel ecosystems. In: Hobbs RJ, Higgs ES, Hall CM (Eds.). Novel Ecosystems: Intervening in the New Ecological World Order. Chichester: Wiley-Blackwell; 2013. p. 58-60.

14. Brancalion PHS, Rodrigues RR, Gandolfi S. Restauração florestal. São Paulo: Oficina de Textos; 2015. $432 \mathrm{p}$.

15. Pacto Pela Restauração Da Mata Atlântica. Grupos de Trabalho Técnico, Científico e de Economia da Restauração. Protocolo de monitoramento para programas e projetos de restauração florestal. 2013. 59 p. Disponível em http://www.pactomataatlantica.org.br/?lang=pt-br\&p=116\#!protocolo-demonitoramento/lbrof (acesso em: 20-VI-2018).

16. Aronson J, Durigan G, BRANCALION PHS. Conceitos e Definições Correlatos à Ciência e à Prática da Restauração Ecológica. IF Série Registros, v. 44, p. 1-38, 2011.

17. Viani RAG, Holl KD, Padovezi A, Strassburg BBN, Farah FT, Garcia LC, Chaves RB, Rodrigues RR, Brancalion PHS. Protocol for Monitoring Tropical Forest Restoration. Tropical Conservation Science. 2017 Apr;10:1-8, doi: 10.1177/1940082917697265

18. Letcher SG, Chazdon RL. Rapid recovery of biomass, species richness, and species composition in a forest chronosequence in northeastern Costa Rica. Biotropica. 2009 Sep;41(5):608-617, doi.org/10.1111/j.1744-7429.2009.00517.x.

19. Arzolla FARDP (Coord.). Plano de Manejo do Parque Estadual da Cantareira. Meio Biótico. Governo do Estado. São Paulo: Secretaria do Meio Ambiente, Instituto Florestal; 2009.

20. Souza FM, Sousa RC, Esteves R, Franco GADC. Flora arbustivo-arbórea do Parque Estadual do Jaraguá, São Paulo - SP. Biota Neotropica. 2009;9(2):187-200. Disponível em: <www.biotaneotropica. org.br/v9n2/en/abstract?iventory+bn00909022009> (acesso em: 25-V-2018).

21. Pivello VR, Peccinini AA. A vegetação do PEFI. In: Bicudo CEM, Forti MC, Bicudo DC (Orgs.). Parque Estadual das Fontes do Ipiranga: uma reserva Biológica na cidade de São Paulo. São Paulo: Secretaria do Meio Ambiente do Estado de São Paulo; 2002. pp. 111-132.

22. Azevedo C. (Coord.). Estratégia Paulista sobre espécies exóticas invasoras. Relatório do Grupo de Trabalho da Resolução SMA 33/2009. v. 1 e 2. São Paulo: SMA/SP - CBRN/DPB/CPA. 2009.

23. Souza SCPM, Silva AG, Franco GADC, Ivanauskas NM. A vegetação secundária em um fragmento florestal urbano: influência de exóticas invasoras na comunidade vegetal. Revista do Instituto Florestal. 2016 Jun;28(1):7-35, doi.org/10.4322/rif.2016.001

24. Arzolla FARDP (Coord.). Plano de Manejo do Parque Estadual Alberto Löfgren. Meio Biótico. Governo do Estado. São Paulo: Secretaria do Meio Ambiente, Instituto Florestal; 2012.

25. Ross JLS, Moroz IC. Mapa geomorfológico do Estado de São Paulo., Mapas e Relatório. São Paulo: FFLCH/USP e IPT/FAPESP. 1997.

26. Oliveira JB, Camargo MN, Rossi M, Calderano-Filho B. Mapa pedológico do Estado de São Paulo: legenda expandida. Campinas: Instituto Agronômico, EMBRAPA Solos; 1999.

27. Baitello JB, Aguiar OD, Rocha FT, Pastore JA, Esteves R. Estrutura fitossociológica da vegetação arbórea da Serra da Cantareira (SP)-Núcleo Pinheirinho. Revista do Instituto Florestal. 1993 $\operatorname{Dec} ; 5(2): 133-161$

28. Ivanauskas NM, Monteiro R, Rodrigues RR. Similaridade florística entre áreas de Floresta Atlântica no Estado de São Paulo. Brazilian Journal of Ecology. 2000 1(4):71-81.

29. Arzolla FARDP, Vilela ESP, Paula GCR, Shepherd GJ, Descio F, Moura C. Composição florística e a conservação de florestas secundárias na Serra da Cantareira, São Paulo, Brasil. Revista Instituto Florestal. 2011 Jun;23(1):149-171.

30. Mueller-Dombois D, Ellenberg H.. Aims and methods of vegetation ecology. New York:John Wiley \& Sons; 1974.547 p.

31. BFG - The Brazil Flora Group. 2018. Brazilian Flora 2020: Innovation and collaboration to meet Target 1 of the Global Strategy for Plant Conservation (GSPC). Rodriguésia 69(4):1513-1527 
32. Gilliam FS, Turrill NL, Aulick SD, Evans DK, Adams MB. Herbaceous layer and soil response experimental acidification in a central Appalachian hardwood forest. Journal of Environmental Quality. 1994 Jul-Aug;23(4):835-844.

33. Moro MF, Souza VC, Oliveira-Filho AT, Queiroz LP, Fraga CN, Rodal MJN, Araújo FS, Martins FR. Alienígenas na sala: o que fazer com espécies exóticas em trabalhos de taxonomia, florística e fitossociologia? Acta Botanica Brasilica. 2012;26(4):991-999, dx.doi.org/10.1590/S010233062012000400029

34. IBGE - Instituto Brasileiro de Geografia e Estatística. Manual Técnico da Vegetação Brasileira. Série Manuais Técnicos em Geociências 1, 2a edição revista e ampliada. Rio de Janeiro: IBGE; 2012. 271 p.

35. INCT - Instituto Nacional de Ciência e Tecnologia. Herbário Virtural de Flora e de Fungos. 2015. Disponível em: <http://inct.splink.org.br.> (acesso em: 23-11-2017).

36. Nalon MA, Lima LMPR, Weingartner P, Souza CHS, Montagna RG, Lima I, Matsukuma CK, Pavão M, Kanashiro MM, Ywane MSS, Teodoro JR, Paschoal E. Sistema de informações florestais do Estado de São Paulo: base de dados georeferenciadas. 2010. Disponível em: <http://www.ambiente.sp.gov.br/sifesp/creditos/>. (acesso em 19-IV-2017).

37. Lockwood L, Hoopes MF, Marchetti MP. Invasion ecology. Oxford: Blackwell Publishing; 2007.301 p.

38. Wanderley MGL, Shepherd GJ, Martins SE, Estrada TEMD, Romanini RP, Koch I, Pirani JR, Melhem TS, Harley AMG, Kinoshita LS, Magenta MAG, Wagner HML, Barros F, Lohmann LG, Amaral MCE, Cordeiro I, Aragaki S, Bianchini RS, Esteves GL. Checklist das Spermatophyta do Estado de São Paulo, Brasil. Biota Neotropica. 2011:11(1a):193-390.

39. I3N BRASIL - Invasives Information Network. Base de dados nacional de espécies exóticas invasoras. Florianópolis: Instituto Hórus de Desenvolvimento e Conservação Ambiental. 2015.Disponível em: <http://i3n.institutohorus.org.br.> (acesso em: 16-VI-2017).

40. CABI - Invasive Species Compendium. Datasheets, maps, images, abstracts and full text on invasive species of the world. Wallingford: CAB International. 2015. Disponível em: 〈http:www.cabi.org/isc> (acesso em: 20-VI-2015).

41. Faegri K, Van der Pijl L. The principles of pollination ecology. 3 ed. New York: Pergamon Press; 1979. $244 \mathrm{p}$.

42. Rech AR, Agostini K, Oliveira PE, Machado IC (Orgs.). Biologia da polinização. Rio de Janeiro: Projeto Cultural; 2014. 527 p.

43. Van der Pijl L. Principles of dispersal in higher plants. 3 ed. Berlim and New York:Springer-Verlag; 1982. $214 \mathrm{p}$.

44. Mamede MCH, Souza VC, Prado J, Barros F, Wanderley MGL, Rando JG. Livro vermelho das espécies vegetais ameaçadas de extinção no Estado de São Paulo. São Paulo:Instituto de Botânica, São Paulo; 2007. 165p.

45. Brasil. Ministério do Meio Ambiente. Lista oficial de espécies brasileiras ameaçadas de extinção. Portaria $\mathrm{n}^{\mathrm{o}}$ 443, de 17/dez/2014, do Ministério do Meio Ambiente. Disponível em: $<$ http://pesquisa.in.gov.br/imprensa/jsp/visualiza/index.jsp?data=18/12/2014\&jornal=1\&pagina=110\& totalArquivos=144>. (acesso em: 29-I-2018).

46. Martinelli G, Moraes MA. Livro vermelho da flora do Brasil. Rio de Janeiro: Instituto de Pesquisas Jardim Botânico do Rio de Janeiro; 2013. 1100 p.

47. International Union for Conservation of Nature - IUCN. Lista vermelha de espécies ameaçadas de extinção da União Internacional para a Conservação da Natureza. Disponível em: <http://iucnredlist.org.> (acesso em: 18-V-2017).

48. Martins FR. Estrutura de uma floresta mesófila. Campinas:Editora da UNICAMP; 1991. 246 p.

49. Shepherd GJ. Fitopac 1, versão 2.1. Campinas: Departamento de Botânica, Universidade Estadual de Campinas. 2005. Disponível em: <https://pedroeisenlohr.webnode.com.br/fitopac/>. (acesso em: 22-X2017).

50. Polisel RT, Ivanauskas NM, Assis MCD, Shepherd GJ, Yamamoto K. Structure of the understory community in four stretches of Araucaria forest in the state of São Paulo, Brazil. Acta Botanica Brasilica. 2014 Jan-Mar;28(1):86-101.

51. Manfra R, Miyamura F, Ivanauskas NM, Souza SCPM. Vegetação Secundária de trecho de Floresta Ombrófila Densa no Parque Estadual Alberto Löfgren: Base de dados de grupos funcionais. figshare. Dataset. 2018. Disponível em:<https://figshare.com/s/479786ab390a4958b600>. (acesso em: 10-V2018).

52. Bawa KS. Plant-pollinator interactions in tropical rain forests. Annual Review of Ecology and Systematics. 1990; 21:399-422. 
53. Tabarelli M, Mantovani W. A regeneração de uma floresta tropical Montana após corte e queima (São Paulo-Brasil). Revista Brasileira de Biologia. 1999; 59(2):239-250, dx.doi.org/10.1590/S003471081999000200008

54. Tabarelli M, Peres CA. Abiotic and vertebrate seed dispersal in Brazilian Atlantic Forest: implications for forest regeneration. Biological Conservation. 2002 Aug;106(2):165-176.

55. Liebsch D, Marques CM, Goldenberg R. How long does the Atlantic Rain Forest take to recover after a disturbance? Changes in species composition and ecological features during secondary succession, Biological Conservation. 2008; 141:1717-1725.

56. Nascimento LM, Sampaio SBEV, Rodal MJN. Secondary succession in a fragmented Atlantic Forest landscape: evidence of structural and diversity convergence along a chronosequence. Journal of Forest Research 2014 Dec;19(6):501-513, doi.org/10.1007/s10310-014-0441-6.

57. Talora DC, Morellato PC.. Fenologia de espécies arbóreas em floresta de planície litorânea do sudeste do Brasil. Revista Brasileira de Botânica. 2000; 23(1):13-26.

58. Campagnoli ML, Santos SRG, Silva SDSR, Antunes AZ. O papel das aves na dispersão e germinação de sementes do pau-incenso (Pittosporum undulatum Vent.) em um remanescente de Mata Atlântica. Revista do Instituto Florestal. 2016 Jun;28(1):59-67.

59. Campagnoli ML, Antunes AZ. Density of invasive exotic palms affecting the understory avifauna in the Atlantic forest, Southeastern Brazil. Neotropical Biology and Conservation 2017 Jan-Apr;12:37-47, doi: 10.4013/nbc.2017.121.05.

60. Antunes AZ, Baitello JB, Campagnoli ML. Birds Consuming fruits of Varronia curassavica Jacq. (Boraginaceae) in Southeastern Brazil (Scientific Note). Revista do Instituto Florestal. 2017 Jun;29(1):129-133, doi:10.24278/2178-5031.201729108.

61. Maciel MDNM, Watzlawick LF, Schoeninger ER, Yamaji FM. Efeito da radiação solar na dinâmica de uma floresta. RECEN-Revista Ciências Exatas e Naturais. 2009; 4(1):101-114.

62. CABI. Invasive Species Compendium. Wallingford, UK: CAB International; 2019. Disponível em:〈www.cabi.org/isc>. (acesso em: 06-VII-2019).

63. Chazdon RL. Renascimento de florestas: regeneração na era do desmatamento. São Paulo: Oficina de Textos; 2016. 432 p.

64. Sampaio AB, Schmidt IB. Espécies Exóticas Invasoras em Universidades de Conservação Federais do Brasil. Número Temático: Diagnóstico e Controle de Espécies Exóticas Invasoras em Áreas Protegidas. Instituto Chico Mendes de Conservação da Biodiversidade. 2013.

65. Guedes RCM, Nogueira NGP, Fusco-Almeida AM, Souza CRF, Oliveira PW. Atividade antimicrobiana de extratos brutos de Petiveria alliacea L. Latin American Journal of Pharmacy 2009; 28(4):520-524.

66. Neves PCP, Bauermann SG, Bitencourt ALV, Souza PA, Marchioretto MS, Bordignon SAL, Mauhs J. Palinoflora do estado do Rio Grande do Sul, Brasil: Phytolaccaceae. BR. Revista Brasileira de Paleontologia. 2006; 9(1):15-26.

67. Pérez-Leal R, García-Mateos MR, Vásquez-Rojas TR, Colinas-León MT. Allelopathic potential of Petiveria alliacea L. Agronomy for sustainable development. 2005; 25(2):177-182.

68. SNUC - Sistema Nacional de Unidades de conservação.. Texto da Lei 9.985 de 18 de julho de 2000 e vetos da presidência da República ao PL aprovado pelo congresso Nacional. Conselho Nacional da Reserva da Biosfera da Mata Atlântica, Cadernos da Reserva da Biosfera da Mata Atlântica: série conservação e áreas protegidas, 18.2 nd; 2000. 76 p.

69. Lino CF, Azevedo CMA, Albuquerque JLR, Costa JPO. Convenção da Diversidade Biológica - CDB: metas de Aichi 2020 e o protocolo de Nagoya (acesso e repartição de benefícios do uso de recursos naturais). São Paulo: Conselho Nacional da Reserva da Biosfera da Mata Atlântica, Cadernos da Reserva da Biosfera da Mata Atlântica: série conservação e áreas protegidas, 41. 2011. 64 p.

70. Marris E, Mascaro J, Ellis EC. Perspective: is everything a novel ecosystem? If so, do we need the concept? In: Hobbs RJ, Higgs ES, Hall CM (Eds.). Novel Ecosystems: Intervening in the New Ecological World Order. Chichester: John Wiley \& Sons; 2013. p. 345-349. 